\title{
Effect of number of medications and use of potentially inappropriate medications on frailty among early-stage older outpatients
}

\author{
Yuya Uragami ${ }^{1 *} \mathbb{D}$, Kazuhiro Takikawa ${ }^{1}$, Hajime Kareki ${ }^{1}$, Koji Kimura ${ }^{1}$, Kazuyuki Yamamoto ${ }^{1}$ and Naomi lihara ${ }^{2}$
}

\begin{abstract}
Background: Frailty is an urgent concern among an aging population worldwide. However, the relationship between frailty and number and types of medications has not been studied in detail among early-stage older patients, and it is unclear what prescriptions may have a role in preventing frailty. This study aimed to clarify the effects of number of medications and use of potentially inappropriate medications (PIMs) on frailty among earlystage older outpatients in Japan.
\end{abstract}

Methods: A cross-sectional study was undertaken. Frailty scores and medications of outpatients aged 65-74 years who regularly visited community pharmacies were investigated. Frailty scores were classified as 0 (non-frailty), 1-2 (pre-frailty), and $\geq 3$ (frailty). The association between frailty and number of medications was analyzed by age and compared between PIM use and non-use groups. The proportion of patients who used PIMs was also analyzed by frailty score.

Results: Of 923 older outpatients, 49 (5.3\%) and 318 (34.5\%) patients had frailty and pre-frailty scores, respectively. The numbers of medications among patients with pre-frailty and frailty were significantly higher than among those with non-frailty ( $p<0.001$ for both). A similar increase was shown for PIM use groups aged 69-71 and 72-74 years, but not for the PIM use group aged 65-68 years and all groups without PIM use. An increasing linear trend was observed for the relationship between the proportion of patients who used any PIM, as well as some subcategories of PIMs (such as NSAIDs, benzodiazepines, loop diuretics and antithrombotic drugs) and frailty score.

Conclusions: Unnecessary medication use among early-stage older outpatients, especially patients aged $\geq 69$ years who use PIMs and many medications, seems to be associated with frailty, but further research is needed to confirm these findings.

Keywords: Frailty, Polypharmacy, Elderly

\section{Background}

Frailty is defined as decreased physiologic reserves and increased vulnerability to adverse health outcomes among older adults [1]. Frailty is known to be associated with an increased risk of functional limitations, falls,

\footnotetext{
* Correspondence: star.onohara@gmail.com

'Star Pharmacy Co., Ltd, 4113-1 Onohara Onohara-cho, Kagawa 769-1611 Kanonji City, Japan

Full list of author information is available at the end of the article
}

hospitalizations, and death [2], resulting in increased use of healthcare resources [3]. Therefore, countermeasures to prevent and treat frailty are of urgent concern in an aging world.

Numerous factors trigger frailty, including nutrition [4], physical activity [5], and various diseases [6]. Some cross-sectional and longitudinal studies [7-9] reported that potentially inappropriate medications (PIMs), defined by criteria such as the Beers criteria 
[10] and the Screening Tool of Older Person's Prescriptions (STOPP) criteria [11], including anticholinergic $[7,8]$ and sedative drugs $[7,9]$, pose a risk of frailty in older people. In addition, the number of medications used by older people [12] is known to be associated with frailty.

The Japan Geriatrics Society published Guidelines for Safe Pharmacotherapy for the Elderly 2005 as an alternative to the Beers and STOPP criteria, and the guidelines reflected the medical and medication situation in Japan; the document was revised as the Screening Tool for Older Person's Appropriate Prescriptions for Japanese (STOPP-J) in 2015 [13]. Only one study, which was conducted among older patients with mild dementia, analyzed the association between PIMs listed in STOPP-J and frailty in Japan [14]. The authors did not find any association between PIMs and frailty, but they did show an association between frailty and reduced quality of life and verbal fluency. Thus, the relationship between frailty and use of PIMs has not been well studied in Japan, although an association between frailty and number of medications has already been found in several studies [15-17].

The number patients with frailty increases greatly after age 75 [18]. To prevent the onset of frailty and control its progression, a study targeting early-stage older people is needed. The present study aimed to clarify the effects of the number of medications and use of PIMs on frailty among early-stage older outpatients in Japan by using STOPP-J.

\section{Methods}

\section{Study population}

This cross-sectional study was undertaken in outpatients aged 65-74 years who (1) visited any of 11 community pharmacies of the Star Pharmacy Group in Kagawa Prefecture in Japan from February to April 2020, (2) visited the same community pharmacies regularly for at least three months before entry into the present study, and (3) provided written informed consent for the study. Those who were certified to need any nursing care support were excluded, because the simple sheet used to measure frailty in the present study, as mentioned below, was developed for patients not receiving nursing care support [19].

The community pharmacies are located near general hospitals and clinics and handle a wide range of medication classes, including those for cardiology, gastroenterology, respiratory, pediatrics, and orthopedics. The study protocol was approved by the ethics committee of Tokushima Bunri University in December 2019 (No. R1-37).

\section{Survey}

Pharmacists in the community pharmacies measured the frailty of participants using a simple sheet developed by Kumagai [19]. The sheet, which has been validated [19], is a questionnaire that has been adapted from the Japanese version of the Fried frailty phenotype [18] to enable healthcare providers to measure frailty easily. The questionnaire consists of five items (fatigue, resistance, ambulation, inactivity, and loss of weight) with response choices of "yes" or "no"; the total score ranges from 0 (no frailty) to 5 (extreme frailty). A total score (frailty score) of $\geq 3$ is considered to indicate frailty. The frailty scores in the present study were grouped into three levels $(0,1-2$, and $\geq 3)$, since the simple sheet by Kumagai [19] was developed based on the Cardiovascular Health Study criteria published by Fried [6], and those criteria employ levels of 0 (non-frailty), 1-2 (prefrailty), and $\geq 3$ (frailty).

Pharmacists also investigated the medications that the participants had been using regularly for more than four weeks. Concomitant medications were investigated by using a prescription notebook that patients carried to the pharmacy and pharmacists completed. These medications included oral medications and insulin products and did not include medications that were used on an as-needed basis or over-the-counter drugs.

The investigated medications were classified as PIMs and not PIMs. PIMs were defined using STOPP-J, and were classified into 19 categories and 28 subcategories (Supplementary Table 1); the categories consisted of antipsychotics, hypnotics, antidepressants, sulpiride, antiparkinson drugs, steroids, antithrombotic drugs (antiplatelet drugs and anticoagulants), digitalis, diuretics, $\beta$-blockers, $\alpha$-blockers, first-generation $\mathrm{H}_{1}$ receptor antagonists, $\mathrm{H}_{2}$ receptor antagonists, antiemetics, laxatives, antidiabetic drugs, insulin, overactive bladder medications, and nonsteroidal anti-inflammatory drugs (NSAIDs). Antipsychotics, selective serotonin reuptake inhibitor (SSRI) antidepressants, steroids, digitalis, $\beta$ blockers, and laxatives are considered PIMs in STOPP-J only in certain cases or in certain subsets of patients (e.g., use of laxatives among patients with impaired renal function), but the present study considered these PIMs in any patients.

\section{Statistical analyses}

The following items were evaluated: (1) gender and age by frailty score level, (2) number of medications by frailty score level, (3) proportion of patients who used PIMs according to frailty score level and (4) number of medications according to frailty score level in the PIM use group (PIMs group) and PIM non-use group (nonPIMs group). The PIMs group included those who used at least one PIM. 
Participants were divided into three age subgroups by tertile: $65-68,69-71$ and $72-74$ years of age, to try to obtain a similar number of patients per subgroup. The relationship between frailty score and the number of medications was assessed for all participants and for these age subgroups. The number of medications was defined as the number of all investigated medications. To investigate the proportion of patients who used PIMs according to frailty score levels, we calculated frailty levels with any PIM and in every subcategory of PIM. Calculating the proportion for each subcategory, we first estimated the correlation coefficients between frailty score level and PIM use for each subcategory and next calculated the proportion of patients who used PIMs, only if the subcategories had a significant correlation coefficient and included 10 or more patients.

The chi-square test for nominal variables and the Cochran-Armitage trend test for ordinal variables were used. The Kruskal-Wallis test and Holm's multiple test were used to compare continuous variables among the three groups. The significance level was established at 0.05. EZR version 1.37 (Saitama Medical Center, Saitama, Japan) [20] was used for statistical analyses.

\section{Results}

Of 926 patients who were informed about the present study, 923 (99.7\%) provided consent and were enrolled in the study. The population included 432 males (46.8\%) and 491 females (53.2\%), and the median age of the entire group was 70 years. In all, there were 49 patients (5.3\%) with frailty (frailty score $\geq 3$ ), 318 patients (34.5\%) with pre-frailty (frailty score 1-2), and 556 patients $(60.2 \%)$ with non-frailty (frailty score 0 ). Concomitant medications were identified in 255 patients (27.6\%) based on the information in their prescription notebooks.

Gender and age by frailty score level are shown in Table 1. There was no difference in gender distribution among patient groups with frailty score levels of $0,1-2$, or $\geq 3(p=0.132)$. However, there was a difference in the proportion of patients included in each age subgroup $(p=0.025)$; the proportion of patients in the 65-68-years age subgroup was likely to be lower among the prefrailty or frailty group than the non-frailty group.

The number of medications by frailty score level is shown in Fig. 1. For all of the early-stage older patients, the number of medications was higher among those with a frailty score of $1-2(p<0.001)$ and $\geq 3(p<0.001)$ than among those with a frailty score of 0 ; the median (interquartile range) numbers of medications for those with a frailty score of $0,1-2$, and $\geq 3$ were $3(2,5), 4(3$, $6)$, and $5(3,7)$. In addition, a higher number of medications with the increase in frailty scores was shown for age subgroups (Fig. 1).

The proportions of patients who used PIMs according to frailty score level are shown in Table 2 . The proportion of patients who used any PIM increased with increasing frailty score $(p<0.001)$; the proportions among frailty score levels $0,1-2$, and $\geq 3$ were $37.4 \%$ (208/556 patients), $56.0 \%$ (178/318 patients), and $69.4 \%$ (34/49 patients), respectively.

The correlations between PIM use of each subcategory and frailty score were weak, although some subcategories showed significant correlations (Supplementary Table 1). PIMs that had the highest correlation coefficients were NSAIDs $(0.162, p<0.001)$, benzodiazepines $(0.114, p<0.001)$, loop diuretics $(0.106, p=0.001)$, and antiplatelet drugs including aspirin $(0.103, p=0.002)$, followed by muscarinic receptor antagonists, multiple antithrombotic drugs, $\mathrm{H}_{2}$ receptor antagonists, sulfonylureas, thiazolidine derivatives and SSRIs. Linear trends for the proportion of patients who used PIMs by increasing frailty score are shown for the PIM subcategories described above (Table 2).

The PIMs and non-PIMs groups included 420 patients (45.5\%) and 503 patients (54.5\%), respectively. Figure 2 shows the number of medications according to frailty score level in the PIMs and non-PIMs groups. Considering all patients in the PIMs group, the number of medications increased with increasing frailty score; the median (interquartile range) numbers for frailty score levels of $0,1-2$, and $\geq 3$ were $5(3,6), 6(4,7)$, and 6.5

Table 1 Gender and Age by Frailty Score Level

\begin{tabular}{|c|c|c|c|c|}
\hline Variables & $\begin{array}{l}\text { Frailty score } 0 \\
n=556 \\
n(\%)\end{array}$ & $\begin{array}{l}\text { Frailty score } 1-2 \\
n=318 \\
n(\%)\end{array}$ & $\begin{array}{l}\text { Frailty score } \geq 3 \\
n=49 \\
n(\%)\end{array}$ & $p$-value ${ }^{\mathrm{a}}$ \\
\hline Gender Male & $275(49.5)$ & $135(42.5)$ & $22(44.9)$ & 0.132 \\
\hline Female & $281(50.5)$ & $183(57.5)$ & $27(55.1)$ & \\
\hline Age, median (interquartile range) & $70(68,72)$ & $71(68.25,72)$ & $70(68,72)$ & \\
\hline $65-68$ years & $197(35.4)$ & $80(25.2)$ & $14(28.6)$ & 0.025 \\
\hline 69-71 years & $193(34.7)$ & $119(37.4)$ & $18(36.7)$ & \\
\hline $72-74$ years & 166 (29.9) & 119 (37.4) & 17 (34.7) & \\
\hline
\end{tabular}

${ }^{\mathrm{a}}$ Chi-square test 


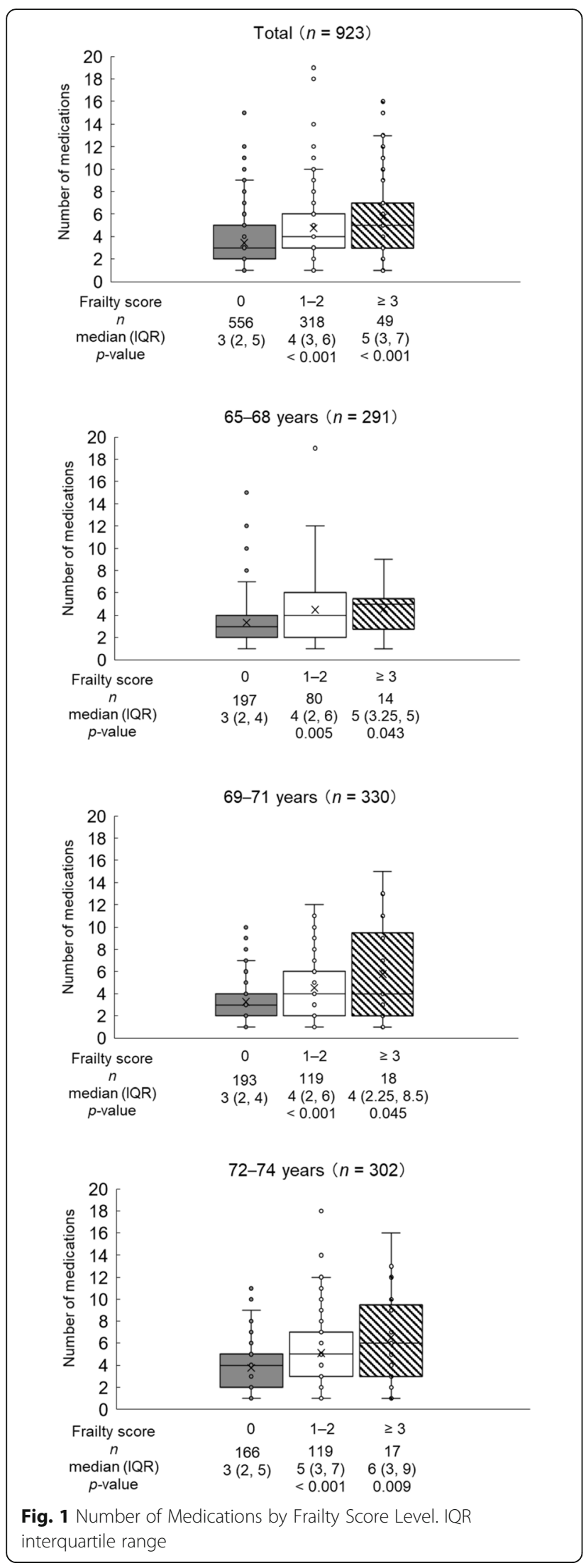

$(4.25,9)$, respectively, and significant differences in the number of medications were observed for comparisons between frailty score levels of 0 and $1-2(p<0.001)$ and between 0 and $\geq 3(p=0.001)$. On the other hand, for all patients in the non-PIMs group, there were significant differences observed for comparisons between frailty score levels 0 and $1-2(p=0.037)$ but not between 0 and $\geq 3(p=0.80)$.

An increase in number of medications according to increased frailty score level was seen for the 69-71-years and the 72-74-years groups in the PIMs group, but no increase was observed for the 65-68-years age subgroup in the PIMs group and all age subgroups in the nonPIMs group (Fig. 2).

\section{Discussion}

The present study evaluating early-stage older outpatients found an association between an increased number of medications and increased frailty score level; this association was noticeable among patients aged 69-74 years in the PIMs group but not in the non-PIMs group. Therefore, patients aged $\geq 69$ years who use PIMs and many medications may need to be closely monitored for unnecessary and inappropriately prolonged medication use.

The findings of the present study require careful interpretation. This study was a cross-sectional study. In addition, some existing reports show an association between PIM use and number of medications [9, 21] and an association between the number of medications and frailty [12]. Besides, numerous factors trigger frailty, such as nutrition [4], physical activity [5], and various diseases [6]. Thus, we cannot assume a direct causal relationship between the use of PIMs and many medications and frailty for early-stage older outpatients. We have not found reports that state whether correcting inappropriate prescriptions, including reducing the number of medications, leads to prevention of frailty. However, approximately $70 \%$ of patients who take 5 or more medications and approximately $80 \%$ of patients who take 10 or more medications are older than 65 years [22], and the number patients with frailty increases greatly after age 75 in Japan [18]. Therefore, further research is needed to confirm these findings and to analyze whether reducing the number of medications and reviewing the use of PIMs from the early stage of older age can help prevent the onset of frailty and control its progression.

On the other hand, polypharmacy appears to affect frailty, and frailty may also affect polypharmacy, as health problems resulting from frailty may lead to a need for additional medications, and diseases associated with frailty may lead to polypharmacy as well. Thus, since prevention of frailty may help to avoid polypharmacy, 
Table 2 Proportion of Patients who Used PIMs by Frailty Score Level

\begin{tabular}{|c|c|c|c|c|c|}
\hline PIM use & $\begin{array}{l}\text { Total } \\
n=923 \\
n(\%)\end{array}$ & $\begin{array}{l}\text { Frailty score } 0 \\
n=556 \\
n(\%)\end{array}$ & $\begin{array}{l}\text { Frailty score } 1-2 \\
n=318 \\
n(\%)\end{array}$ & $\begin{array}{l}\text { Frailty score } \geq 3 \\
n=49 \\
n(\%)\end{array}$ & $p$-value \\
\hline Any PIM & $420(45.5)$ & $208(37.4)$ & $178(56.0)$ & $34(69.4)$ & $<0.001$ \\
\hline \multicolumn{6}{|l|}{ PIMs } \\
\hline NSAIDs & $71(7.7)$ & $24(4.3)$ & $38(11.9)$ & $9(18.4)$ & $<0.001$ \\
\hline Benzodiazepines $^{\mathrm{b}}$ & $90(9.8)$ & $40(7.2)$ & $40(12.6)$ & $10(20.4)$ & $<0.001$ \\
\hline Loop diuretics & $16(1.7)$ & $3(0.5)$ & $12(3.8)$ & $1(2.0)$ & 0.004 \\
\hline \multicolumn{6}{|l|}{ Antithrombotic drugs } \\
\hline Antiplatelet drugs including aspirin & $84(9.1)$ & $36(6.5)$ & $44(13.8)$ & $4(8.2)$ & 0.007 \\
\hline Combined therapy with multiple antithrombotic drugs & $21(2.3)$ & $7(1.3)$ & $13(4.1)$ & $1(2.0)$ & 0.04 \\
\hline Muscarinic receptor antagonists & $26(2.5)$ & $10(1.8)$ & $12(3.8)$ & $4(8.2)$ & 0.006 \\
\hline $\mathrm{H}_{2}$ receptor antagonists & $30(3.3)$ & $12(2.2)$ & $15(4.7)$ & $3(6.1)$ & 0.02 \\
\hline Sulfonylureas & $39(4.2)$ & $17(3.1)$ & $18(5.7)$ & $4(8.2)$ & 0.021 \\
\hline Thiazolidine derivatives & $11(1.2)$ & $3(0.5)$ & $7(2.2)$ & $1(2.0)$ & 0.039 \\
\hline SSRIS & $12(1.3)$ & $4(0.7)$ & $6(1.9)$ & $2(4.1)$ & 0.025 \\
\hline
\end{tabular}

a Cochran-Armitage trend test

${ }^{\mathrm{b}}$ Including use as antianxiety drugs and hypnotics

NSAIDs non-steroidal anti-inflammatory drugs; PIMs potentially inappropriate medications; SSRIs selective serotonin reuptake inhibitors

healthcare providers should strive to prevent frailty to minimize the likelihood and adverse effects of polypharmacy.

The present study found some associations between PIM subcategories and frailty. Subcategories such as NSAIDs [23], benzodiazepines [7, 9], muscarinic receptor antagonists [7, 8], and SSRIs [24] have been associated with frailty in previous studies. For medications in other subcategories, we could not find reports of associations with frailty, so it is unclear whether the medications are the direct cause of the frailty. However, adverse drug events related to the medications cause frailty: falls with loop diuretics [25] or sulfonylureas [26], bone loss with loop diuretics [27], cognitive decline with $\mathrm{H}_{2}$ receptor antagonists [28], and osteoporosis with thiazolidine derivatives [29]. Additionally, pathophysiology and conditions that accompanied the use of the medications may have an effect on frailty; for example, diabetes mellitus, pulmonary diseases, and cardiovascular disease are known to be associated with frailty [6]. No report of a direct or indirect effect of antiplatelet drugs on frailty exists, as far as we could determine from searches of the literature.

The present study found the association between number of medications and frailty in all age subgroups of early-stage older patients. Previous studies [8, 30-37] found an association between increased number of medications and frailty for people 65 years of age and older, but all of the previous studies included late-stage older patients: they did not target only early-stage older patients and did not analyze a subgroup of early-stage older age. The present study has an advantage since the association was proven for the early-stage older population.

Some limitations must be considered for the present study. First, the survey was conducted in community pharmacies in Kagawa Prefecture in Japan. However, the median number of medications among patients with frailty was 5 in the entire population and 6.5 in the PIMs group, similar to the results of a previous study that reported the use of 6 or more medications was a high risk for frailty [38]. Second, we are aware that the cutoff points of the age subgroups and the small sample sizes of the groups may have influenced the results. We tried to divide the number of patients into age subgroups of similar size using tertiles and to find an appropriate age cutoff that made the number of patients more even by moving the cutoff value of one tertile to the next age subgroup, but we could not achieve an equal number of patients among the subgroups. Thus, the age cutoff point itself does not have any specific implication, such as on biology and clinical pharmacology. Third, medication dose and laboratory data of renal and hepatic function affect outcomes of medication therapy and might possibly affect frailty, but that information was not analyzed in the present study. Additionally, concomitant medications were investigated in the present study based on information recorded by a pharmacist in a prescription notebook carried by the patient, but the medications may not have been accurately recorded, and adherence to those medications was unclear.

Fourth, the present study counted PIMs without restriction of patients, although STOPP-J [13] restricts patients for some subcategories of PIMs. Thus, the present 


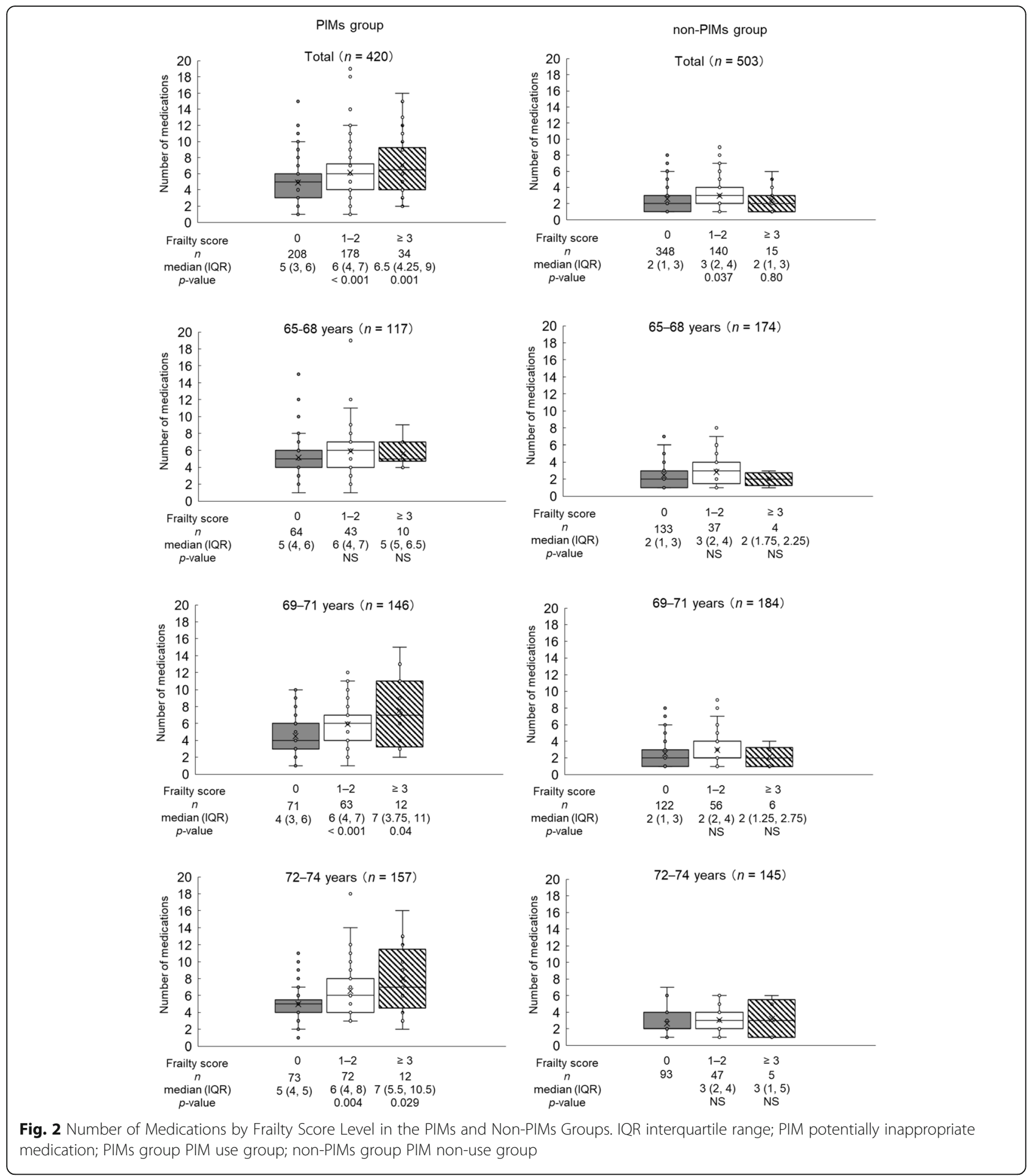

study may have overestimated exposure to PIMs. Fifth, a seasonal bias for frailty evaluation may exist, since the patient entry period in the present study was limited to three months, and older people are considered to be likely to exercise less and to stay indoors in the summer and winter.

\section{Conclusions}

The present study targeting early-stage older outpatients found that the association between an increased number of medications and frailty was observed among outpatients aged 69 years and older who used PIMs, but not among those who did not 
use PIMs. Further research is needed to confirm these findings and analyze whether correcting inappropriate prescriptions, including reducing the number of medications, from the early stage of older age can help prevent the onset of frailty and control its progression.

\section{Abbreviations}

PIM: Potentially inappropriate medication; STOPP: Screening Tool for Older Persons' Prescriptions; STOPP-J: Screening Tool for Older Persons' Appropriate Prescriptions for Japanese; NSAID: Nonsteroidal antiinflammatory drug; SSRI: Selective serotonin reuptake inhibitor

\section{Supplementary Information}

The online version contains supplementary material available at https://doi. org/10.1186/s40780-021-00195-x.

Additional file 1: Supplementary Table 1. Correlation Coefficients between PIM Use and Frailty Score Level. We estimated the correlation between frailty score level and PIM use for each subcategory.

\section{Acknowledgements}

None.

\section{Authors' contributions}

YU conceived of the study and design, and analyzed the data. KT, HK, KK, and KY contributed to data collection. YU drafted the manuscript. NI assisted in the preparation of the manuscript. All authors contributed to the critical revision of the manuscript and approved the final revision.

\section{Funding}

This research received no specific grant from any funding agency in the public, commercial, or not-for-profit sectors.

\section{Availability of data and materials}

The datasets used and/or analyzed during the current study are available from the corresponding author on reasonable request.

\section{Declarations}

\section{Ethics approval and consent to participate}

Written informed consent was obtained from all participants. All procedures followed were in accordance with the ethics committee of Tokushima Bunri University in December 2019 (No. R1-37).

\section{Consent for publication}

Not applicable.

\section{Competing interests}

The authors declare that they have no competing interests.

\section{Author details}

'Star Pharmacy Co., Ltd, 4113-1 Onohara Onohara-cho, Kagawa 769-1611 Kanonji City, Japan. ${ }^{2}$ Kagawa School of Pharmaceutical Sciences, Tokushima Bunri University, 1314-1 Shido, Sanuki City, Kagawa 769-2193, Japan.

Received: 28 December 2020 Accepted: 24 February 2021 Published online: 03 May 2021

\section{References}

1. Clegg A, Young J, lliffe S, Rikkert MO, Rockwood K. Frailty in elderly people. Lancet. 2013;381:752-62. https://doi.org/10.1016/S0140-6736(12)62167-9.

2. Vermeiren S, Vella-Azzopardi R, Beckwée D, Habbig AK, Scafoglieri A, Jansen B, Bautmans I. Gerontopole Brussels Study group. Frailty and the Prediction of Negative Health Outcomes: A Meta-Analysis. J Am Med Dir Assoc. 2016; 17:1163.e1-e17. https://doi.org/10.1016/j.jamda.2016.09.010.
3. Sirven N, Rapp T. The dynamics of hospital use among older people evidence for Europe using SHARE data. Health Serv Res. 2017;52:1168-84. https://doi.org/10.1111/1475-6773.12518.

4. Lorenzo-López L, Maseda A, de Labra C, Regueiro-Folgueira L, RodríguezVillamil JL, Millán-Calenti JC. Nutritional determinants of frailty in older adults: a systematic review. BMC Geriatr. 2017;17:108. https://doi.org/10.11 86/s12877-017-0496-2

5. Peterson MJ, Giuliani C, Morey MC, Pieper CF, Evenson KR, Mercer V, Cohen HJ, Visser M, Brach JS, Kritchevsky SB, Goodpaster BH, Rubin S, Satterfield S, Newman AB, Simonsick EM. Health, Aging and Body Composition Study Research Group. Physical activity as a preventative factor for frailty: the health, aging, and body composition study. J Gerontol A Biol Sci Med Sci. 2009;64:61-8. https://doi.org/10.1093/gerona/gln001.

6. Fried LP, Tangen CM, Walston J, Newman AB, Hirsch C, Gottdiener J, Seeman T, Tracy R, Kop WJ, Burke G, McBurnie MA. Cardiovascular Health Study Collaborative Research Group Frailty in older adults: evidence for a phenotype. J Gerontol A Biol Sci Med Sci. 2001;56:M146-56. https://doi. org/10.1093/gerona/56.3.m146.

7. Muhlack DC, Hoppe LK, Saum KU, Haefeli WE, Brenner H, Schöttker B. Investigation of a possible association of potentially inappropriate medication for older adults and frailty in a prospective cohort study from Germany. Age Ageing. 2019;49:20-5. https://doi.org/10.1093/ageing/afz127.

8. Herr M, Sirven N, Grondin H, Pichetti S, Sermet C. Frailty, polypharmacy, and potentially inappropriate medications in old people: findings in a representative sample of the French population. Eur J Clin Pharmacol. 2017; 73:1165-72. https://doi.org/10.1007/s00228-017-2276-5.

9. Jamsen KM, Bell JS, Hilmer SN, Kirkpatrick CM, llomäki J, Le Couteur D, Blyth FM, Handelsman DJ, Waite L, Naganathan V, Cumming RG, Gnjidic D. Effects of changes in number of medications and drug burden index exposure on transitions between frailty states and death: the Concord health and ageing in men project cohort study. J Am Geriatr Soc. 2016;64:89-95. https:/doi.org/10.1111/jgs.13877.

10. Beers MH, Ouslander JG, Rollingher I, Reuben DB, Brooks J, Beck JC. Explicit criteria for determining inappropriate medication use in nursing home residents. UCLA division of geriatric medicine. Arch Intern Med. 1991:151:1825-32.

11. Gallagher P, Ryan C, Byrne S, Kennedy J, O'Mahony D. STOPP (screening tool of older Person's prescriptions) and START (screening tool to alert doctors to right treatment). Consensus validation. Int I Clin Pharmacol Ther. 2008:46:72-83. https://doi.org/10.5414/cpp46072.

12. Gutiérrez-Valencia M, Izquierdo M, Cesari M, Casas-Herrero Á, Inzitari M, Martínez-Velilla $\mathrm{N}$. The relationship between frailty and polypharmacy in older people: a systematic review. Br J Clin Pharmacol. 2018;84:1432-44. https://doi.org/10.1111/bcp.13590.

13. Kojima T, Mizukami K, Tomita N, Arai H, Ohrui T, Eto M, Takeya Y, Isaka Y, Rakugi H, Sudo N, Arai H, Aoki H, Horie S, Ishii S, Iwasaki K, Takayama S, Suzuki Y, Matsui T, Mizokami F, Furuta K, Toba K, Akishita M, Working Group on Guidelines for Medical Treatment and its Safety in the Elderly. Screening Tool for Older Persons' Appropriate Prescriptions for Japanese: Report of the Japan Geriatrics Society Working Group on "Guidelines for medical treatment and its safety in the elderly". Geriatr Gerontol Int. 2016;16:9831001. https://doi.org/10.1111/ggi.12890.

14. Huang $\mathrm{CH}$, Umegaki $\mathrm{H}$, Watanabe $\mathrm{Y}$, Kamitani $\mathrm{H}$, Asai A, Kanda S, Nomura $\mathrm{H}$, Kuzuya M. Potentially inappropriate medications according to STOPP-J criteria and risks of hospitalization and mortality in elderly patients receiving home-based medical services. PLoS One. 2019;14:e0211947. https://doi.org/1 0.1371/journal.pone.0211947.

15. Bonfiglio V, Umegaki $H$, Kuzuya M. Potentially inappropriate medications and Polypharmacy: a study of older people with mild cognitive impairment and mild dementia. J Alzheimers Dis. 2019;71:889-97. https://doi.org/1 0.3233/JAD-190284.

16. Yuki A, Otsuka R, Tange C, Nishita Y, Tomida M, Ando F, Shimokata H. Polypharmacy is associated with frailty in Japanese community-dwelling older adults. Geriatr Gerontol Int. 2018;18:1497-500. https:/doi.org/10.1111/ggi.13507.

17. Takeuchi H, Uchida HA, Kakio Y, Okuyama Y, Okuyama M, Umebayashi R, Wada K, Sugiyama H, Sugimoto K, Rakugi H, Wada J. The prevalence of frailty and its associated factors in Japanese hemodialysis patients. Aging Dis. 2018;9:192-207. https://doi.org/10.14336/AD.2017.0429.

18. Satake S, Shimada H, Yamada M, Kim H, Yoshida H, Gondo Y, Matsubayashi K, Matsushita E, Kuzuya M, Kozaki K, Sugimoto K, Senda K, Sakuma M, Endo N, Arai $\mathrm{H}$. Prevalence of frailty among community-dwellers and outpatients in Japan as defined by the Japanese version of the cardiovascular health study criteria. Geriatr Gerontol Int. 2017;17:2629-34. https://doi.org/10.1111/ggi.13129. 
19. Chen S, Chen T, Kishimoto H, Susaki Y, Kumagai S. Development of a Fried frailty phenotype questionnaire for use in screening community-dwelling older adults. J Am Med Dir Assoc. 2020;21:272-6. https://doi.org/10.1016/j.ja mda.2019.07.015.

20. Kanda Y. Investigation of the freely available easy-to-use software 'EZR' for medical statistics. Bone Marrow Transplant. 2013:48:452-8. https://doi.org/1 0.1038/bmt.2012.244

21. Moriarty F, Hardy C, Bennett K, Smith SM, Fahey T. Trends and interaction of polypharmacy and potentially inappropriate prescribing in primary care over 15 years in Ireland: a repeated cross-sectional study. BMJ Open. 2015;5: e008656. https://doi.org/10.1136/bmjopen-2015-008656.

22. Onoue H, Koyama T, Zamami Y, Hagiya H, Tatebe Y, Mikami N, Shinomiya K, Kitamura Y, Hinotsu S, Sendo T, Ouchi Y, Kano MR. Trends in Polypharmacy in Japan: a Nationwide retrospective study. J Am Geriatr Soc. 2018;66:226773. https://doi.org/10.1111/jgs.15569.

23. Martinot $P$, Landré B, Zins M, Goldberg M, Ankri J, Herr M. Association between potentially inappropriate medications and frailty in the early old age: a longitudinal study in the GAZEL cohort. J Am Med Dir Assoc. 2018; 19:967-73. https://doi.org/10.1016/j.jamda.2018.07.008.

24. Lakey SL, LaCroix AZ, Gray SL, Borson S, Williams CD, Calhoun D, Goveas JS, Smoller JW, Ockene JK, Masaki KH, Coday M, Rosal MC, Woods NF. Antidepressant use, depressive symptoms, and incident frailty in women aged 65 and older from the Women's Health Initiative observational study. J Am Geriatr Soc. 2012;60:854-61. https://doi.org/10.1111/j.1532-5415.2012.03 940.x.

25. Butt DA, Mamdani M, Austin PC, Tu K, Gomes T, Glazier RH. The risk of falls on initiation of antihypertensive drugs in the elderly. Osteoporos Int. 2013; 24:2649-57. https://doi.org/10.1007/s00198-013-2369-7.

26. Lapane $\mathrm{KL}$, Jesdale BM, Dubé CE, Pimentel CB, Rajpathak SN. Sulfonylureas and risk of falls and fractures among nursing home residents with type 2 diabetes mellitus. Diabetes Res Clin Pract. 2015;109:411-9. https://doi.org/1 0.1016/j.diabres.2015.05.009.

27. Lim LS, Fink HA, Blackwell T, Taylor BC, Ensrud KE. Loop diuretic use and rates of hip bone loss and risk of falls and fractures in older women. J Am Geriatr Soc. 2009;57:855-62. https://doi.org/10.1111/j.1532-5415.2009.02195. $\mathrm{x}$.

28. Hanlon JT, Landerman LR, Artz MB, Gray SL, Fillenbaum GG, Schmader KE. Histamine2 receptor antagonist use and decline in cognitive function among community dwelling elderly. Pharmacoepidemiol Drug Saf. 2004;13: 781-7. https://doi.org/10.1002/pds.952.

29. Schwartz AV, Sellmeyer DE, Vittinghoff E, Palermo L, Lecka-Czernik B, Feingold KR, Strotmeyer ES, Resnick HE, Carbone L, Beamer BA, Park SW, Lane NE, Harris TB, Cummings SR. Thiazolidinedione use and bone loss in older diabetic adults. J Clin Endocrinol Metab. 2006;91:3349-54. https://doi. org/10.1210/jc.2005-2226.

30. Çakmur H. Frailty among elderly adults in a rural area of Turkey. Med Sci Monit. 2015;21:1232-42. https://doi.org/10.12659/MSM.893400.

31. Merchant RA, Chen MZ, Tan LWL, Lim MY, Ho HK, van Dam RM. Singapore Healthy Older People Everyday (HOPE) Study: Prevalence of Frailty and Associated Factors in Older Adults. J Am Med Dir Assoc. 2017;18:734.e9-e14. https://doi.org/10.1016/j.jamda.2017.04.020.

32. Saum KU, Schöttker B, Meid AD, Holleczek B, Haefeli WE, Hauer K, Brenner $H$. Is Polypharmacy associated with frailty in older people? Results from the ESTHER cohort study. J Am Geriatr Soc. 2017;65:e27-32. https://doi.org/1 $0.1111 /$ jgs. 14718 .

33. Rosted E, Schultz M, Sanders S. Frailty and polypharmacy in elderly patients are associated with a high readmission risk. Dan Med J. 2016;63:A5274.

34. Woo J, Yu R, Wong M, Yeung F, Wong M, Lum C. Frailty screening in the community using the FRAIL scale. J Am Med Dir Assoc. 2015;16:412-9. https://doi.org/10.1016/j.jamda.2015.01.087.

35. Eyigor S, Kutsal YG, Duran E, Huner B, Paker N, Durmus B, Sahin N, Civelek GM, Gokkaya K, Doğan A, Günaydın R, Toraman F, Cakir T, Evcik D, Aydeniz A, Yildirim AG, Borman P, Okumus M, Ceceli E, Turkish Society of Physical Medicine and Rehabilitation, Geriatric Rehabilitation Working Group. Frailty prevalence and related factors in the older adult-FrailTURK Project. Age (Dordr). 2015;37:9791. https://doi.org/10.1007/s11357-015-9791-z.

36. Buttery AK, Busch MA, Gaertner B, Scheidt-Nave C, Fuchs J. Prevalence and correlates of frailty among older adults: findings from the German health interview and examination survey. BMC Geriatr. 2015;15:22. https://doi.org/1 0.1186/s12877-015-0022-3.
37. Chang Cl, Chan DC, Kuo KN, Hsiung CA, Chen CY. Prevalence and correlates of geriatric frailty in a northern Taiwan community. J Formos Med Assoc. 2011;110:247-57. https://doi.org/10.1016/S0929-6646(11)60037-5.

38. Moulis F, Moulis G, Balardy L, Gérard S, Sourdet S, Rougé-Bugat ME, Lapeyre-Mestre M, Montastruc JL, Rolland Y, Vellas B. Searching for a polypharmacy threshold associated with frailty. J Am Med Dir Assoc. 2015; 16:259-61. https://doi.org/10.1016/j.jamda.2014.11.016.

\section{Publisher's Note}

Springer Nature remains neutral with regard to jurisdictional claims in published maps and institutional affiliations.
Ready to submit your research? Choose BMC and benefit from:

- fast, convenient online submission

- thorough peer review by experienced researchers in your field

- rapid publication on acceptance

- support for research data, including large and complex data types

- gold Open Access which fosters wider collaboration and increased citations

- maximum visibility for your research: over $100 \mathrm{M}$ website views per year

At BMC, research is always in progress.

Learn more biomedcentral.com/submissions 